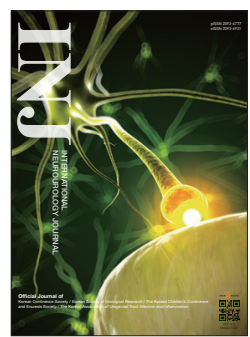

\title{
Practical Aspects of Botulinum Toxin-A Treatment in Patients With Overactive Bladder Syndrome
}

\author{
Chun-Hou Liao, ${ }^{1}$ Hann-Chorng Kuo ${ }^{2}$ \\ ${ }^{1}$ Department of Urology, Cardinal Tien Hospital and Fu-Jen Catholic University, New Taipei, Taiwan \\ ${ }^{2}$ Department of Urology, Buddhist Tzu Chi General Hospital and Tzu Chi University, Hualien, Taiwan
}

\begin{abstract}
Intravesical onabotulinumtoxin $\mathrm{A}$ (BoNT-A) injection is an effective treatment for overactive bladder syndrome (OAB) that is refractory to antimuscarinics. An injectable dose of $100 \mathrm{U}$ has been suggested to achieve the optimal balance of benefit and safety in patients with OAB. BoNT-A (total volume of $10 \mathrm{~mL}$ ) was administered as evenly distributed intradetrusor injections $(5 \mathrm{U})$ across 20 sites approximately $1 \mathrm{~cm}$ apart $(0.5 \mathrm{~mL}$ per site) using a flexible or rigid cystoscope. Treatment with BoNT-A was generally well tolerated by most patients, and most treatment-related adverse events were localized to the urinary tract. The prevalence of $\mathrm{OAB}$ increases with age, and elderly patients are more vulnerable to complications. The short-term efficacy of intravesical BoNT-A injection for refractory $\mathrm{OAB}$ with no treatment-related complications in the elderly population has been documented. Frail elderly patients can experience the same treatment results, such as significantly improved urgent urinary incontinence and quality of life, as young and nonfrail elderly patients with 100-U BoNT-A injections. However, increased risk of larger postvoid residual (PVR) urine and lower long-term success rates were noted in frail elderly patients; around $11 \%$ had acute urinary retention, while $60 \%$ had PVR urine volume $>150 \mathrm{~mL}$ after treatment. In addition, intravesical injection of BoNT-A effectively decreased urgency symptoms in elderly patients with OAB and central nervous system lesions. The adverse effects were acceptable, while the long-term effects were comparable to those in patients with OAB without central nervous system lesions. Nonetheless, the possibility of longstanding urinary retention and chronic catheterization in this vulnerable population requires careful evaluation before treatment with intravesical BoNT-A. In conclusion, the current findings indicate that intravesical BoNT-A is an effective and safe treatment for $\mathrm{OAB}$ in elderly patients.
\end{abstract}

Keywords: Urinary Bladder, Overactive; Botulinum Toxins, Type A; Aged

- Conflict of Interest: No potential conflict of interest relevant to this article was reported.

\section{INTRODUCTION}

Conservative measures and oral medications such as muscarinic receptor antagonists or $\beta 3$-adrenoceptor agonists are the first-line treatments for overactive bladder syndrome $(\mathrm{OAB})$ $[1,2]$. However, insufficient efficacy and/or intolerable adverse effects (AEs) are associated problems in some patients despite effective symptom relief [3,4]. Intravesical onabotulinumtoxinA (BoNT-A) injection is an effective treatment for patients with $\mathrm{OAB}$ or idiopathic detrusor overactivity (IDO) that is refractory to antimuscarinics [5-10]. The indications and contraindications of intravesical BoNT-A for OAB are summarized in Table 1. An injectable dose of $100 \mathrm{U}$ has been recommended to achieve an optimal balance between benefit and safety in pa-
Corresponding author: Hann-Chorng Kuo (iD http://orcid.org/0000-0001-7165-4771 Department of Urology, Buddhist Tzu Chi General Hospital, 707, Section 3, Chung-Yang Road, Hualien, Taiwan

E-mail: hck@tzuchi.com.tw / Tel: +886-3-8561825 / Fax: +886-3-8560794

- Chun-Hou Liao (iD http://orcid.org/0000-0002-7340-110X

Submitted: September 19, 2015 / Accepted after revision: November 2, 2015
This is an Open Access article distributed under the terms of the Creative Commons Attribution Non-Commercial License (http://creativecommons.org/licenses/by-nc/3.0/) which permits unrestricted non-commercial use, distri-
bution, and reproduction in any medium, provided the original work is properly cited. 
tients with $\mathrm{OAB}$, while a dose of $50 \mathrm{U}$ did not show results different from those of placebo in double-blind, dose-ranging trials $[7,8]$. In addition, postvoid residual (PVR) urine volumes $>200 \mathrm{~mL}$ were more commonly noted in patients treated with BoNT-A doses $>150 \mathrm{U}$ [11]. A clinical research program that

Table 1. Indications and contraindications of intravesical BoNT-A for OAB

\section{Indications \\ Confirm a diagnosis of $\mathrm{OAB}$ \\ Confirm failure on anticholinergic therapy \\ No recent (within 12 weeks) botulinum toxin injections for any indication \\ In patients not catheterizing, assess willingness and ability to catheterize \\ Contraindications \\ Ongoing urinary tract infection \\ Acute urinary retention at the time of treatment (if not routinely catheterizing), \\ Unwillingness or inability to initiate catheterization posttreatment if required \\ Known hypersensitivity to botulinum toxin type A or any of the components.}

BoNT-A, onabotulinumtoxinA; OAB, overactive bladder syndrome. comprised 2 large phase III, randomized, placebo-controlled studies showed that treatment with 100-U BoNT-A was generally well tolerated, and most treatment-related AEs were localized to the urinary tract $[9,10]$. However, widespread use of this treatment is limited by increased PVR urine volume and urinary tract infections (UTIs), problems that have yet to be resolved [12-14].

\section{INJECTION TECHNIQUES}

The injection methods, including location and depth, number of sites, and volume at each site, varied among previous studies. Currently, the most commonly recommended dose of BoNT-A for $\mathrm{OAB}$ is $100 \mathrm{U}$ (total volume of $10 \mathrm{~mL}$ ), and should be administered as evenly distributed intradetrusor injections (5 $\mathrm{U}$ ) across 20 sites approximately $1 \mathrm{~cm}$ apart $(0.5 \mathrm{~mL}$ per injection site; Fig. 1A) using a flexible or rigid cystoscope [15]. The trigone of the bladder is usually spared of the injection. The instillation of local anesthetics into the bladder and/or general sedation during the treatment can also be used.

Regarding injection location, Kuo [16] reported that bladder base/trigone injections are as safe and effective as bladder body
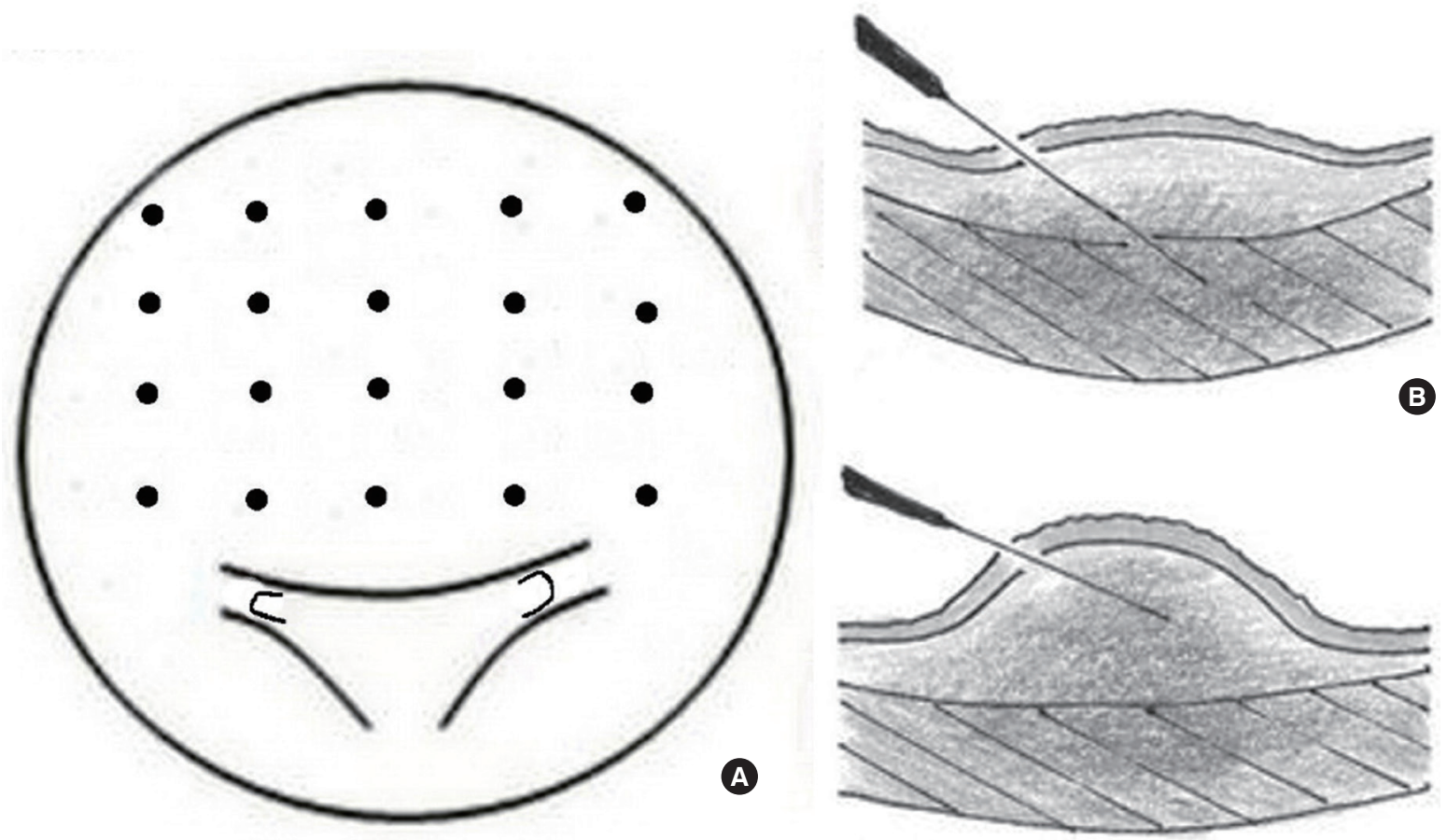

c

Fig. 1. (A) Intravesical onabotulinumtoxinA was administered as evenly distributed injections across 20 sites, (B) intradetrusor injection, (C) suburothelial injection. 
injections with or without trigone involvement in a singleblind, randomized, paralleled, active controlled trial. Another randomized controlled trial also investigated the efficacy and safety of intravesical BoNT-A injections with trigone inclusion [17]. The results of these trials support that intravesical BoNTA injections at different sites are effective and safe regardless of trigone sparing or inclusion. The diffusion pattern of BoNT-A in guinea pig bladders was investigated by examining the expression of the cleaved form of $25-\mathrm{kDa}$ synaptosome-associated protein (cSNAP-25) with different injection volumes and administration protocols [18]. A single BoNT-A injection could spread the neurotoxin activity to the opposite side of the bladder. Injection volume, rather than injection number, may be another important determinant of the diffusion and action of BoNT-A in the bladder. Liao et al. [19] prospectively compared the therapeutic effects and safety of different numbers of BoNTA injections for patients with OAB. Different injection numbers produced similar therapeutic outcomes and AEs. These researchers suggested that $1-\mathrm{mL}$ BoNT-A injections (10U) at 10 sites were adequate for achieving an optimal therapeutic effect in patients with $\mathrm{OAB}$.

As observed in previous studies, injection depth also varied and depended to some extent on the length of the needle-tip [15]. Although intradetrusor injection remains the standard treatment technique approved by the Food and Drug Administration (Fig. 1B) $[14,15]$, suburothelial injection is another choice that reportedly prevents extravasation of BoNT-A (Fig. 1C) [20]. Another study conducted by Krhut et al. [21] also compared the effects of suburothelial and intradetrusor injections of BoNT-A for neurogenic IDO. Although the results in both groups were comparable, the researchers favored the suburothelial injection technique because it allowed more precise toxin localization.

\section{CLINICAL EFFICACY}

Both the phase III trials $(n=1,105)$ included patients with $\geq 3$ urge urinary incontinence (UUI) episodes over 3 days, $>8$ micturition episodes per day, $\leq 100 \mathrm{~mL}$ of PVR urine volume, and those whose symptoms were not adequately managed with anticholinergics $[9,10]$. Statistically significant and clinically relevant reductions in all $\mathrm{OAB}$ symptoms were found after intravesical BoNT-A treatment. A 3- to 4-fold greater reduction from baseline in the mean daily frequency of UI episodes was reported at week 12 with BoNT-A vs. placebo ( -2.65 vs. -0.87 , $\mathrm{P}<0.001)$ that corresponded to mean percentage reductions from the baseline of $47.9 \%$ with BoNT-A vs. $12.5 \%$ with placebo. A higher proportion of BoNT-A-treated patients reported a positive response (greatly improved or improved) vs. placebotreated patients $(60.8 \%$ vs. $29.2 \%, \mathrm{P}<0.001)$ [10]. Chapple et al. [9] observed similar positive findings of BoNT-A treatment significantly decreasing the number of UI episodes per day, and the reduction from baseline was greater than that with placebo (-2.95 for BoNT-A vs. -1.03 for placebo, $\mathrm{P}<0.001)$. Treatment with BoNT-A also significantly improved daily micturition episodes, urgency episodes, and nocturia (Table 2). Improvement in patient's quality of life (QoL) was also reportedly associated with clinically meaningful improvements in OAB symptoms after BoNT-A treatment $[9,10]$. In addition, improvements in $\mathrm{OAB}$ symptoms were observed in patients with UI regardless of the number of anticholinergic therapies used or the reason for inadequate $\mathrm{OAB}$ management [22]. In another retrospective study, BoNT-A injections were shown to be more effective in patients with anticholinergic intolerability than in those with

Table 2. Clinical efficacy of intravesical BoNT-A for OAB in phase III trials

\begin{tabular}{|c|c|c|c|c|}
\hline \multirow{2}{*}{ Variable } & \multicolumn{2}{|c|}{095 Study [10] $(\mathrm{n}=557)$} & \multicolumn{2}{|c|}{520 Study [9] $(\mathrm{n}=548)$} \\
\hline & BoNT-A & Placebo & BoNT-A & Placeba \\
\hline \multicolumn{5}{|c|}{ Mean changes of from baseline to 12 weeks } \\
\hline Urinary incontinence episodes/day & -2.65 & -0.87 & -2.95 & -1.03 \\
\hline Micturition episodes/day & -2.15 & -0.91 & -2.56 & -0.83 \\
\hline Urgency episodes/day & -2.93 & -1.21 & -3.27 & -0.84 \\
\hline Nocturia episodes/day & -0.45 & -0.24 & -0.54 & -0.25 \\
\hline Voided volume/micturition (mL) & 41.1 & 9.7 & - & - \\
\hline \multicolumn{5}{|c|}{ Proportion of patients reported positive response (\%) } \\
\hline Greatly improved or improved & 60.8 & 29.2 & 62.8 & 26.8 \\
\hline
\end{tabular}

BoNT-A, onabotulinumtoxinA; OAB, overactive bladder syndrome. 
poor medication efficacy ( $86 \%$ vs. $60 \%, \mathrm{P}=0.02$ ) [23].

Cui et al. [24] documented a systematic review and metaanalysis regarding the efficacy and safety of BoNT-A for treating idiopathic OAB. Compared to the outcomes with placebo, the mean number of daily UI episodes decreased ( -2.77 vs. $-1.01, \mathrm{P}<0.00001)$; mean number of daily micturition episodes decreased ( -1.61 vs. $-0.87, \mathrm{P}<0.00001)$; maximum cystometric capacity (MCC) increased ( 91.39 vs. $32.32, \mathrm{P}<0.00001)$; volume of voided urine increased (44.29 vs. 7.36, $\mathrm{P}<0.00001$ ), while $29.20 \%$ (BoNT-A) vs. $7.95 \%$ (placebo) of patients became incontinence-free (odds ratio [OR], 4.89; $\mathrm{P}<0.00001$ ) after BoNT-A treatment [24]. Another updated systematic review reported that BoNT-A treatment leads to significant improvement in bladder daily parameters such as daily frequency $(-29 \%)$, daily urgency $(-38 \%)$, and daily incontinence $(-59 \%)$ (all $\mathrm{P}<0.02)$. The urodynamic parameters of MCC and maximum detrusor pressure improved by $58 \%(\mathrm{P}=0.04)$ and $-29 \%$ $(\mathrm{P}=0.002)$, respectively [25].

A total of 839 patients were evaluated in a long-term, openlabel extension study (clinical trial identifier: NCT00915525) to evaluate long-term efficacy of BoNT-A treatment [26]. A reinjection was performed upon patient's request after 2 UI episodes in a 3-day void diary. Patients experienced consistent response with re-treatments for all efficacy endpoints from treatment cycle 3 . In the subset of 345 patients who reached week 12 of treatment cycle 3 , the mean reductions in daily frequency of UI were $-3.07,-3.49$, and -3.49 episodes at week 12 after the first, second, and third BoNT-A treatments, respectively. The corresponding proportions of patients with a positive treatment response were $63.6 \%, 76.9 \%$, and $77.3 \%$, respectively [27].

Dowson et al. [28] collected prospective data regarding repeated injections of $200 \mathrm{U}$ of BoNT-A from a single center. A total of 207 injections were administered to 100 patients. All patients took 1 injection, 53 took 2, 20 took 3, 13 took 4, 10 took 5,5 took 6,3 took 7,1 took 8,1 took 9 , and 1 took 10 injections. A statistically significant reduction in frequency, urgency, and UUI was observed after the first BoNT-A injection compared to baseline. This improvement was maintained after repeated injections and did not vary statistically between injection-periods. Thirty-seven patients stopped treatment after the first 2 injections; thereafter, dropouts were rare. The most common reasons for discontinuing treatment were poor efficacy (13\%) and clean intermittent catheterization (CIC)-related issues (11\%). The incidence of CIC after the first injection was $35 \%$. Bacteriuria was detected in $21 \%$ of patients. The mean in- terinjection interval was 322 days [28]. Mohee et al. [29] also observed that two-thirds of the patients discontinued treatment because of treatment-associated tolerability issues.

\section{SAFETY AND TOLERABILITY}

Treatment with BoNT-A was generally well tolerated, and most AEs were localized to the urinary tract. Uncomplicated UTI was the most frequently reported $\mathrm{AE}$ in both phase III studies: $15.5 \%$ with BoNT-A vs. $5.9 \%$ with placebo [10] and $24.1 \%$ with BoNT-A vs. 9.6\% with placebo [9]. In both the studies, a change from baseline in PVR urine volume $\geq 200 \mathrm{~mL}$ was found in $8.7 \%$ and $8.8 \%$ of patients in the BoNT-A group, $6.1 \%$ and $6.9 \%$ of patients initiated CIC $[9,10]$. In a systematic review and meta-analysis, BoNT-A was often associated with complications resulting from PVR $(\mathrm{P}<0.00001)$, UTI $(\mathrm{P}<0.00001)$, and CIC $(\mathrm{P}<0.00001)$ [24]. The risk of UTI significantly increased to $21 \%$ in the BoNT-A group and was $7 \%$ in the placebo group $(\mathrm{P}<0.001)$; the risk of intermittent self $\mathrm{CIC}$ increased from $0 \%$ to $12 \%(\mathrm{P}<0.001)$ [24].

In an interim analysis of a long-term extension study in which 253 patients had reached week 12 of treatment cycle 3, the proportion of patients reporting urinary retention was stable after every BoNT-A treatment cycle, with 4.0\%, 3.4\%, and $3.2 \%$ reporting it after cycles 1,2 , and 3 , respectively. The proportion of patients requiring CIC due to increased PVR urine volume also remained stable, with $4.6 \%, 4.1 \%$, and $4.7 \%$ requiring it after cycles 1, 2, and 3, respectively [27]. Kuo et al. [12] investigated the risk factors for increased AEs after BoNT-A injection in patients with IDO. Male sex, baseline PVR urine volume $\geq 100 \mathrm{~mL}$, comorbidity, and BoNT-A dose $>100 \mathrm{U}$ are risk factors for increased incidence of AEs. In another retrospective analysis, Osborn et al. [13] observed that an increased preoperative PVR urine volume was a risk factor for urinary retention.

\section{BONT-A TREATMENT IN SPECIFIC PATIENT GROUPS}

\section{Elderly}

The prevalence of $\mathrm{OAB}$ increases with age, and elderly patients are more vulnerable to complications. These patients usually exhibit altered drug solubility, metabolism, and clearance as well as increased prevalence of polypharmacy that may impact disease management [30]. White et al. [31] investigated the 
short-term efficacy of intravesical 200 U BoNT-A injection in treatment of refractory $\mathrm{OAB}$ with no treatment-related complications in the elderly population. Liao and Kuo [32] reported that the same treatment results as those in younger and nonfrail elderly patients, such as significant improvement of UUI and QoL, can be obtained in frail elderly individuals using 100-U BoNT-A. However, an increased risk of large PVR urine volume and lower long-term success rates were noted in the frail elderly patients. Around $60 \%$ of frail elderly individuals had PVR urine volume $>150 \mathrm{~mL} ; 11 \%$ had acute urinary retention after treatment.

\section{Patients With Diabetes Mellitus}

One epidemiological study showed that diabetes mellitus (DM) is an independent precipitating factor for $\mathrm{OAB}$, and diabetic patients may have bothersome $\mathrm{OAB}$ symptoms that require medical assistance. Wang et al. [33], in an age-matched casecontrol study, investigated the efficacy and safety of intravesical BoNT-A 100-U injection in patients with DM and refractory IDO. Successful results were noted at the 6-month follow-up (DM 56\% vs. non-DM 61\%, P=0.128). Diabetic patients had significantly greater incidences of large PVR volumes (DM [60.4\%] vs. non-DM [33.3\%], $\mathrm{P}=0.007)$ and general weakness (DM [10.4\%] vs. non-DM [0\%], P = 0.03) after treatment. Baseline urodynamic parameters in patients with DM did not predict the occurrence of AEs. No major complication was noted in either group.

\section{Patients With Central Nervous System Lesions}

Degeneration of the central nervous system (CNS) in the elderly has been proposed as a pathogenic factor of $\mathrm{OAB}$ [34]. Jiang et al. [35] evaluated the efficacy and safety of intravesical 100-U BoNT-A treatment in elderly patients with chronic cerebrovascular accidents, Parkinson disease, and dementia. Intravesical injection of BoNT-A effectively decreased urgency symptoms in elderly patients of $\mathrm{OAB}$ with CNS lesions. The AEs were acceptable, while the long-term effects were comparable to those in patients of $\mathrm{OAB}$ without CNS lesions. Nonetheless, the possibility of longstanding urinary retention and chronic catheterization requires careful evaluation in this vulnerable population before intravesical BoNT-A treatment is chosen.

\section{CONCLUSIONS}

Intravesical BoNT-A is an effective treatment for OAB or IDO in elderly patients. The current recommended dose is $100 \mathrm{U}$ administered as evenly distributed intradetrusor injections (5 $\mathrm{U})$ across 20 sites using a flexible or rigid cystoscope. Treatment was generally well tolerated, and most treatment-related AEs were localized to the urinary tract.

\section{REFERENCES}

1. Gormley EA, Lightner DJ, Burgio KL, Chai TC, Clemens JQ, Culkin DJ, et al. Diagnosis and treatment of overactive bladder (non-neurogenic) in adults: AUA/SUFU guideline. J Urol 2012;188(6 Suppl):2455-63.

2. Oelke M, Bachmann A, Descazeaud A, Emberton M, Gravas S, Michel MC, et al. EAU guidelines on the treatment and follow-up of non-neurogenic male lower urinary tract symptoms including benign prostatic obstruction. Eur Urol 2013;64:118-40.

3. Wagg A, Compion G, Fahey A, Siddiqui E. Persistence with prescribed antimuscarinic therapy for overactive bladder: a UK experience. BJU Int 2012;110:1767-74.

4. Chancellor MB, Migliaccio-Walle K, Bramley TJ, Chaudhari SL, Corbell C, Globe D. Long-term patterns of use and treatment failure with anticholinergic agents for overactive bladder. Clin Ther 2013;35:1744-51.

5. Sahai A, Dowson C, Khan MS, Dasgupta P. Improvement in quality of life after botulinum toxin-A injections for idiopathic detrusor overactivity: results from a randomized double-blind placebo-controlled trial. BJU Int 2009;103:1509-15.

6. Fowler CJ, Auerbach S, Ginsberg D, Hale D, Radziszewski P, Rechberger $\mathrm{T}$, et al. OnabotulinumtoxinA improves health-related quality of life in patients with urinary incontinence due to idiopathic overactive bladder: a 36-week, double-blind, placebo-controlled, randomized, dose-ranging trial. Eur Urol 2012;62:148-57.

7. Dmochowski R, Chapple C, Nitti VW, Chancellor M, Everaert K, Thompson C, et al. Efficacy and safety of onabotulinumtoxinA for idiopathic overactive bladder: a double-blind, placebo controlled, randomized, dose ranging trial. J Urol 2010;184:2416-22.

8. Denys P, Le Normand L, Ghout I, Costa P, Chartier-Kastler E, Grise P, et al. Efficacy and safety of low doses of onabotulinumtoxi$\mathrm{nA}$ for the treatment of refractory idiopathic overactive bladder: a multicentre, double-blind, randomised, placebo-controlled doseranging study. Eur Urol 2012;61:520-9.

9. Chapple C, Sievert KD, MacDiarmid S, Khullar V, Radziszewski P, Nardo C, et al. OnabotulinumtoxinA $100 \mathrm{U}$ significantly improves all idiopathic overactive bladder symptoms and quality of life in patients with overactive bladder and urinary incontinence: a ran- 
domised, double-blind, placebo-controlled trial. Eur Urol 2013;64: 249-56.

10. Nitti VW, Dmochowski R, Herschorn S, Sand P, Thompson C, Nardo $\mathrm{C}$, et al. OnabotulinumtoxinA for the treatment of patients with overactive bladder and urinary incontinence: results of a phase 3, randomized, placebo controlled trial. J Urol 2013;189:2186-93.

11. Rovner E, Kennelly M, Schulte-Baukloh H, Zhou J, Haag-Molkenteller C, Dasgupta P. Urodynamic results and clinical outcomes with intradetrusor injections of onabotulinumtoxinA in a randomized, placebo-controlled dose-finding study in idiopathic overactive bladder. Neurourol Urodyn 2011;30:556-62.

12. Kuo HC, Liao CH, Chung SD. Adverse events of intravesical botulinum toxin a injections for idiopathic detrusor overactivity: risk factors and influence on treatment outcome. Eur Urol 2010;58:91926.

13. Osborn DJ, Kaufman MR, Mock S, Guan MJ, Dmochowski RR, Reynolds WS. Urinary retention rates after intravesical onabotulinumtoxinA injection for idiopathic overactive bladder in clinical practice and predictors of this outcome. Neurourol Urodyn 2015; 34:675-8.

14. Cox L, Cameron AP. OnabotulinumtoxinA for the treatment of overactive bladder. Res Rep Urol 2014;6:79-89.

15. Rovner E. Chapter 6: practical aspects of administration of onabotulinumtoxinA. Neurourol Urodyn 2014;33 Suppl 3:S32-7.

16. Kuo HC. Bladder base/trigone injection is safe and as effective as bladder body injection of onabotulinumtoxinA for idiopathic detrusor overactivity refractory to antimuscarinics. Neurourol Urodyn 2011;30:1242-8.

17. Manecksha RP, Cullen IM, Ahmad S, McNeill G, Flynn R, McDermott TE, et al. Prospective randomised controlled trial comparing trigone-sparing versus trigone-including intradetrusor injection of abobotulinumtoxinA for refractory idiopathic detrusor overactivity. Eur Urol 2012;61:928-35.

18. Coelho A, Dinis P, Pinto R, Gorgal T, Silva C, Silva A, et al. Distribution of the high-affinity binding site and intracellular target of botulinum toxin type A in the human bladder. Eur Urol 2010;57:884-90.

19. Liao CH, Chen SF, Kuo HC. Different number of intravesical onabotulinumtoxinA injections for patients with refractory detrusor overactivity do not affect treatment outcome: a prospective randomized comparative study. Neurourol Urodyn 2015 Apr 24 [Epub]. http://dx.doi.org/10.1002/nau.22780.

20. Kuo HC. Comparison of effectiveness of detrusor, suburothelial and bladder base injections of botulinum toxin a for idiopathic detrusor overactivity. J Urol 2007;178(4 Pt 1):1359-63.

21. Krhut J, Samal V, Nemec D, Zvara P. Intradetrusor versus suburo- thelial onabotulinumtoxinA injections for neurogenic detrusor overactivity: a pilot study. Spinal Cord 2012;50:904-7.

22. Sievert KD, Chapple C, Herschorn S, Joshi M, Zhou J, Nardo C, et al. OnabotulinumtoxinA 100U provides significant improvements in overactive bladder symptoms in patients with urinary incontinence regardless of the number of anticholinergic therapies used or reason for inadequate management of overactive bladder. Int J Clin Pract 2014;68:1246-56.

23. Makovey I, Davis T, Guralnick ML, O'Connor RC. Botulinum toxin outcomes for idiopathic overactive bladder stratified by indication: lack of anticholinergic efficacy versus intolerability. Neurourol Urodyn 2011;30:1538-40.

24. Cui Y, Zhou X, Zong H, Yan H, Zhang Y. The efficacy and safety of onabotulinumtoxinA in treating idiopathic OAB: a systematic review and meta-analysis. Neurourol Urodyn 2015;34:413-9.

25. Mangera A, Apostolidis A, Andersson KE, Dasgupta P, Giannantoni A, Roehrborn C, et al. An updated systematic review and statistical comparison of standardised mean outcomes for the use of botulinum toxin in the management of lower urinary tract disorders. Eur Urol 2014;65:981-90.

26. Irish Pharmaceutical Healthcare Association (IPHA). Botox 100 Unit Summary of Product Characteristics [Internet]. Dublin (IE): IPHA; [cited 2015 Aug 26]. Available from: http://www.medicines. ie/medicine/15243/SPC/BOTOX+100+Unit/.

27. Cruz F, Nitti V. Chapter 5: clinical data in neurogenic detrusor overactivity (NDO) and overactive bladder (OAB). Neurourol Urodyn 2014;33 Suppl 3:S26-31.

28. Dowson C, Watkins J, Khan MS, Dasgupta P, Sahai A. Repeated botulinum toxin type A injections for refractory overactive bladder: medium-term outcomes, safety profile, and discontinuation rates. Eur Urol 2012;61:834-9.

29. Mohee A, Khan A, Harris N, Eardley I. Long-term outcome of the use of intravesical botulinum toxin for the treatment of overactive bladder (OAB). BJU Int 2013;111:106-13.

30. Oefelein MG. Safety and tolerability profiles of anticholinergic agents used for the treatment of overactive bladder. Drug Saf 2011;34:73354.

31. White WM, Pickens RB, Doggweiler R, Klein FA. Short-term efficacy of botulinum toxin a for refractory overactive bladder in the elderly population. J Urol 2008;180:2522-6.

32. Liao $\mathrm{CH}$, Kuo HC. Increased risk of large post-void residual urine and decreased long-term success rate after intravesical onabotulinumtoxinA injection for refractory idiopathic detrusor overactivity. J Urol 2013;189:1804-10.

33. Wang CC, Liao CH, Kuo HC. Diabetes mellitus does not affect the 
efficacy and safety of intravesical onabotulinumtoxina injection in patients with refractory detrusor overactivity. Neurourol Urodyn 2014;33:1235-9.

34. Andersson KE. Mechanisms of Disease: central nervous system involvement in overactive bladder syndrome. Nat Clin Pract Urol
2004;1:103-8.

35. Jiang YH, Liao CH, Tang DL, Kuo HC. Efficacy and safety of intravesical onabotulinumtoxinA injection on elderly patients with chronic central nervous system lesions and overactive bladder. PLoS One 2014;9:e105989. 